\title{
Amadeus
}

International Multidisciplinary Journal ISSN 2525-8281

V.3, N.6, 2019. p.01-08. - ISSN 2525-8281

\section{Grynfeltt Hernia initially diagnosed as Lipoma: A Case Report}

\author{
Raniery Soares Sobreira \\ Machado ${ }^{l}$, Abstract: Lumbar hernia is a disease that presents unsual and difficult \\ Raquel Carlos de Brito ${ }^{2}$, \\ Jairo Fernandes Frutuosos, \\ André Luís Sant'Anna', \\ Francisco Anselmo \\ Magalhães ${ }^{5}$ \\ Vital Maria dos Santos \\ Sobreira Machado ${ }^{6}$, \\ Hermes Melo Teixeira Batista ${ }^{7}$ \\ diagnosis. It is most prevalent in males and the elderly. It is presented the \\ case of a 70-year-old male patient with previous trauma in the lumbar region \\ 30 years ago and since then presented as a tumor in that region. He asked for \\ a medical help and, initially, his case was diagnosed as a lipoma, but then \\ Grynfeltt's hernia was identified and properly repaired. \\ Keywords: Lumbar hernia; Grynfeltt hernia; superior lumbar hernia
}

\section{Introduction}

Hernia is defined as an abnormal protrusion of tissue or organ to another anatomical region, but not to its original place, due to a fibromuscular failure or through a natural hole. Most hernias occur in the anterior abdominal wall, mainly in the inguinal region. However, they may occur in other places such as the femoral, umbilical, lateral abdomen and lumbar region (Zanini, Timoner and Machado Filho, 2004).

\footnotetext{
${ }^{1}$ Regional Hospital of Cariri - Ceará, Brazil;

${ }^{2}$ Federal University of Campina Grande - Cajazeiras, Brazil;

Contact: quelbrito1987@gmail.com;

${ }^{3}$ Regional Hospital of Cariri - Ceará, Brazil;

${ }^{4}$ Regional Hospital of Cariri - Ceará, Brazil;

${ }^{5}$ São Francisco Hospital - Serra Talhada, Brazil;

${ }^{6}$ São Francisco Hospital - Serra Talhada, Brazil;

${ }^{7}$ Regional Hospital of Cariri - Ceará, Brazil. College Hospital Júlio Bandeira - Cajazeiras, Brazil.
} 
Lumbar hernia is a rare condition that comes up from a failure in the fibromuscular fascia of the posterior wall of the abdomen (Renck, Gomes and Lopes Junior, 2009; Alcoforado, Lira, et al., 2013). It corresponds to 1.5 to $2 \%$ of all abdominal wall hernias, and about 300 cases have been reported in the literature until 2007 (Matos, Orioli, et al., 2011; Renck, Gomes and Lopes Junior, 2009).

It occurs in two sites, basically: in the superior lumbar triangle (Grynfelt space) $(95 \%)$ or in the lower lumbar triangle (Petit space), which are areas of relative weakness in the posterolateral abdominal wall. Most of them are due to non-traumatic or congenital acquired etiologies (Renck, Gomes and Lopes Junior, 2009; Alcoforado, Lira, et al., 2013; Pereira, Souza, et al., 2012).

It is a disease with simple diagnosis, but often not correctly diagnosed or misdiagnosed, because this disease is little known by most physicians (Alcoforado, Lira, et al., 2013).

Lumbar hernia can be acquired or congenital type. When it is congenital, it usually manifests in childhood and may be associated with other hereditary disorders such as lumbar vertebral deficiency syndrome, meningocele and neurofibromatosis. Some causes of acquired lumbar hernia type include penetrating wounds, pregnancy, tuberculosis, bone graft removal, poliomyelitis, obesity and extreme malnutrition. Acquired lumbar hernia type can also be divided into primary or secondary.

The primary oneoccurs mainly in men in the ratio of 3: 1 woman, on the left side (2: 1) and in the triangle of Grynfeltt and occurs in elderly people in situations of increased intra-abdominal pressure, chronic bronchitis and excessive loss of weight. On the other hand, the secondary acquired lumbar hernia type represents less than $25 \%$ of the hole lumbar hernias and it's caused by surgical procedure, open trauma, closed trauma, lumbar abscess and neurovascular injury that leads to muscular atrophy (Renck, Gomes and Lopes Junior, 2009, Matos, Orioli et al.).

In this study, it's reported a case of acquired secondary lumbar hernia, called Grynfeltt type, in an elderly male patient with lumbar trauma 30 years ago. 


\section{Case Report}

Male patient, 70 years old, farmer, native of Milagres, State of Ceará, Brazil. He called for help in surgery ambulatory to investigate a tumor in the superior left lumbar region, thinking that this could be just a lipoma. The tumor had fibroelastic consistency that increased to physical efforts and, clinically, the patient complains about its painful and uncomfortable to the efforts. He also says that tumor usually disappeared from time to time. Patient with previous history of trauma in the lumbar region 30 years ago, since then had bulging in the referred region.

During the surgical procedure, after the incision, the surgeon identified a defect in the muscular wall, with the presence of perirenal fat, and then he thought that it could be a lumbar hernia. He immediately referred the patient to a surgical center to repair that hernia.

Patient laid in the right lateral decubitus position; the incision was longitudinal on the left flank. The hernia was identified in dorsal trine, in the superior lumbar region (called Grynfeltt). The failure was corrected with the apposition of polypropylene mesh. The patient progressed well in the postoperative period, being discharged 24 hours.

Figure 01: Patient in right lateral decubitus, with incision in left flank region, where the tumor was present.

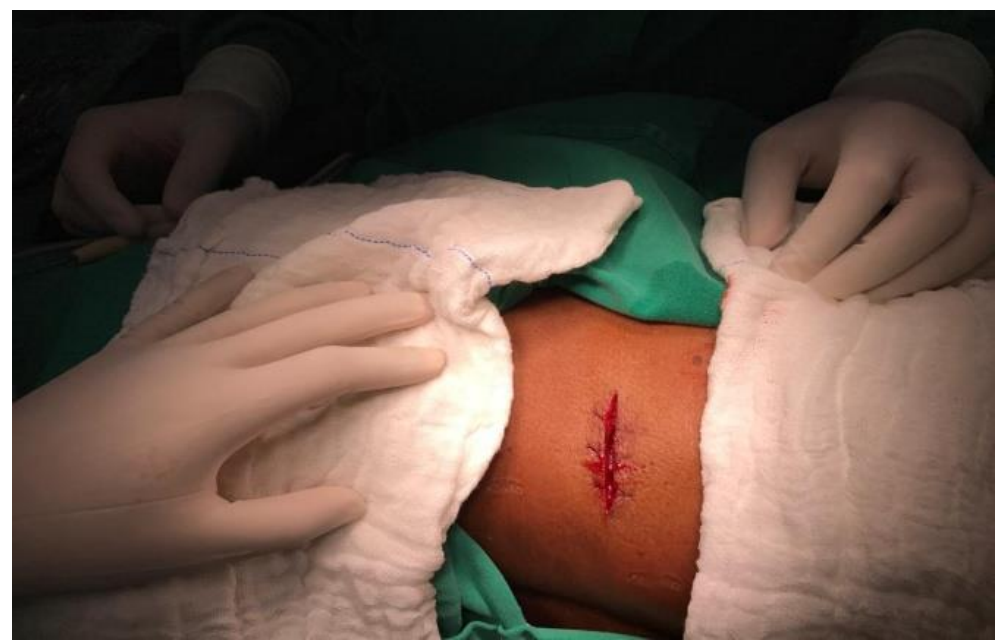


Figure 02: Failure of the transverse abdominal muscle.

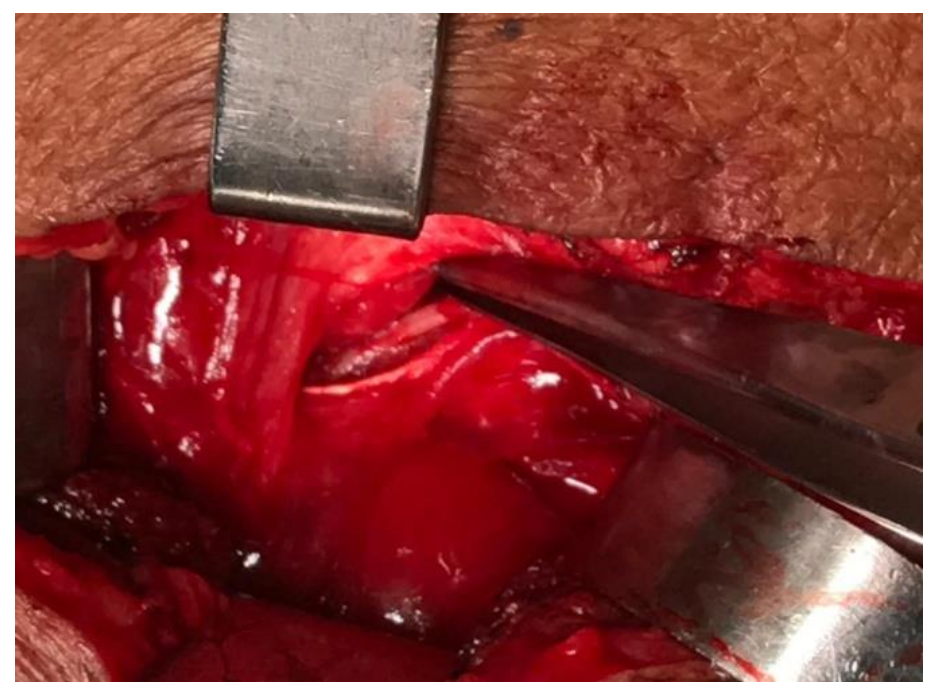

Figure 03: Perirenal fat. Content that lumbar hernia.

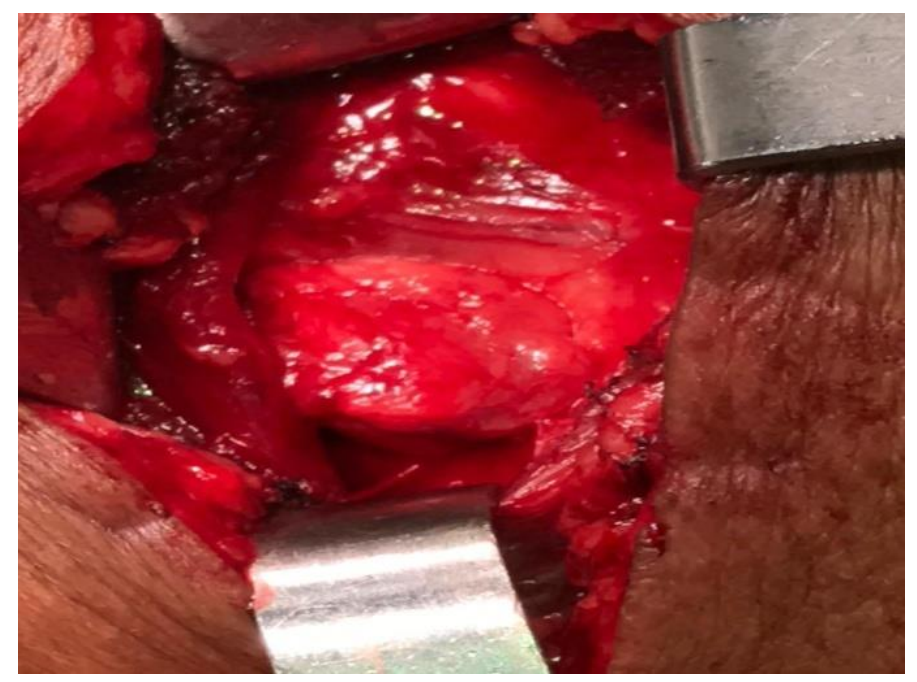

Figure 04: Correction of muscular failure, with apposition of polypropylene mesh.

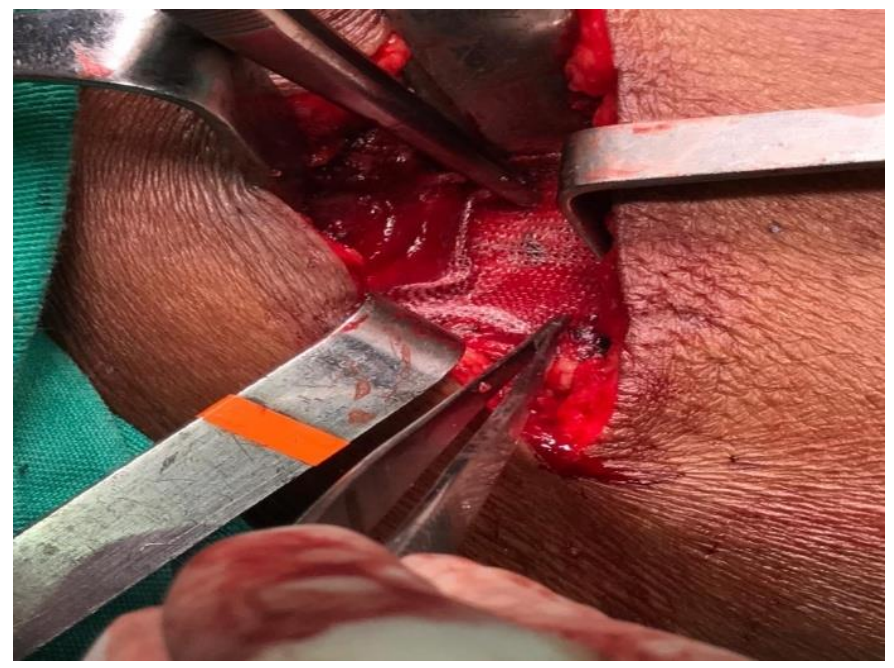


The lumbar hernias are a lumbar tumor, with a softened consistency, capable of being reducible, sometimes not. They are predominantly on the left side and the triangle of Grynfeltt, occurring more in males between 50 and 70 years old (Alcoforado, Lira, et al., 2013; Renck, Gomes and Lopes Junior, 2009; Pereira, Souza, et al. al., 2012).

The spontaneous lumbar hernias are mostly unilateral and two times more frequent on the left side of the body. Lumbar hernias bilateral are very rare and can be congenital defects (Alcoforado, Lira, et al., 2013; Pereira, Souza, et al., 2012).

Primary acquired lumbar hernia type is caused by weakness of the posterior abdominal wall and is more frequent in the elderly, in excess weight loss and in situations of intra-abdominal pressure increase, corresponding to $50 \%$ of the cases. The secondary acquired lumbar hernia type (30\%) is due to previous operations, infections, trauma or retroperitoneal hematomas. The remaining $20 \%$ is caused by congenital origin, most found in children (Alcoforado, Lira, et al., 2013; Pereira, Souza, et al., 2012).

There are in the back areas of anatomical fragility that help the appearance of the lumbar hernias, such as the holes of the posterior branches of the lumbar nerves and vascular structures, holes in the fascia secondary to trauma or problem in embryological development. There are two prominent regions, the Grylfeltt space or superior lumbar triangle, delimited by the lower border of the 12th rib, para-spinal muscles and internal oblique muscle, covered by the latus muscle of the dorsum and the fascia of the transverse muscle of the abdomen on the floor of this triangle; and Petit space or lower lumbar triangle that is formed by the latus muscle of the dorsum, external oblique muscle and iliac crest, whose floor is formed by the transverse fascia, internal oblique muscle aponeurosis, lumbodorsal fascia and covered by the superficial lumbodorsal fascia (Alcoforado, Lira, et al., 2013).

The retroperitoneal fat, intestinal loops, kidneys and other viscera can protrude through the hernia defect and can lead to incarceration $(25 \%)$ or strangulation $(10 \%)$ (Pereira, Souza et al., 2012; Alcoforado, Lira et al., 2013).

The clinical of lumbar hernias will manifest with the majority of patients complaining about discomfort or pain in the lumbar region, but some of them are just asymptomatic. These patients will present bulges in the posterior region of the abdomen that accentuate with the increase of intra-abdominal pressure and disappear with ventral decubitus (Alcoforado, Lira, et al., 2013). 
The diagnosis is based on anamnesis and physical examination of the patient, but the few of clinical manifestations makes them go unnoticed sometimes, even to the careful physical examination, especially in obese patients with small hernias (Renck, Gomes and Lopes Junior, 2009). At physical examination, the area of fragility can be perceived through palpation, which can be painful, and the increased lumbar mass volume to Valsalva test or other conditions that increase intra-abdominal pressure (Alcoforado, Lira, et al.., 2013). Among the differential diagnosis are: Soft tissue tumors, bruises, lipoma, muscle contracture, post-traumatic abscesses or postoperative ones and renal tumors. However, these masses are less painful and not deductible, but as similarity of lumbar hernia, the mass grows with elevated intra-abdominal pressure (Renck, Gomes and Lopes Junior, 2009; Matos, Orioli, et al., 2011).

Diagnostic confirmation can be done by imaging tests. Computed tomography shows the muscular layers of the posterior wall as well and the wall defect, regardless of whether there is hernial content. Ultrasonography can be used in the suspicion of lumbar hernia, and that is the diagnostic test more accessible compared to computed tomography (Renck, Gomes and Lopes Junior, 2009; Alcoforado, Lira, et al., 2013).

Figure 05: Example of how Grynfeltt hernia can appear on computed tomography. In this example: herniated kidney to the right through the superior lumbar triangle (Renck, Gomes and Lopes Junior, 2009).

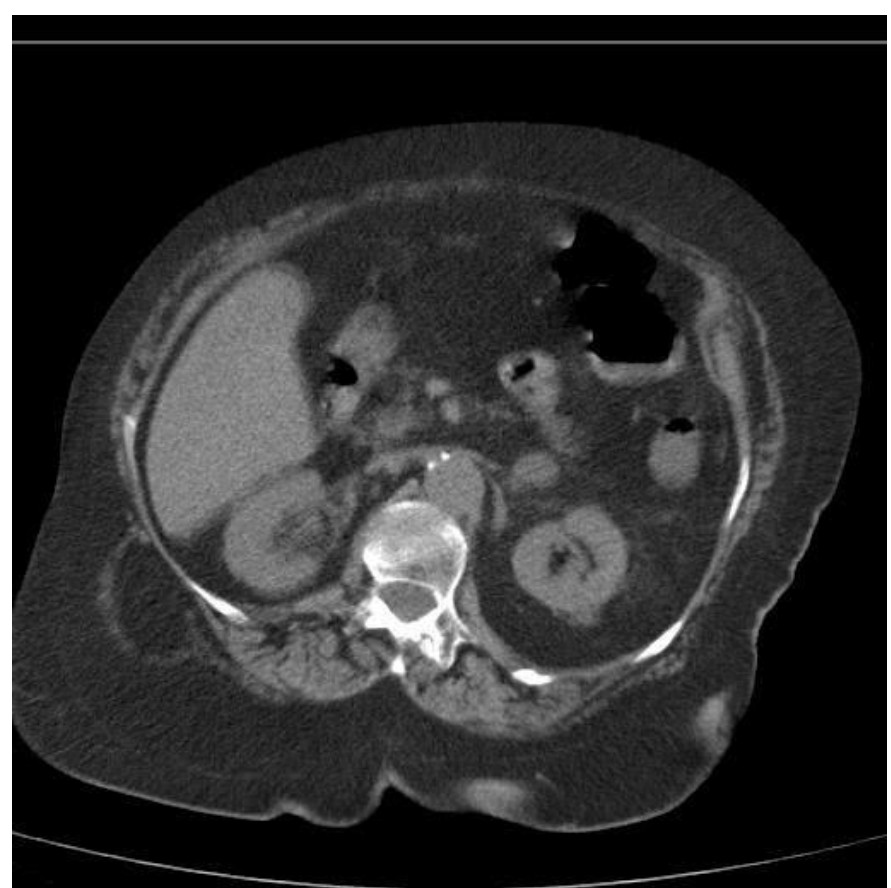


Figure 06: Example of how the Grynfeltt hernia can appear on computed tomography. In this example: small intestine and mesenteric fat herniated to the left through the superior lumbar triangle (Alves, Silva, et al., 2011).

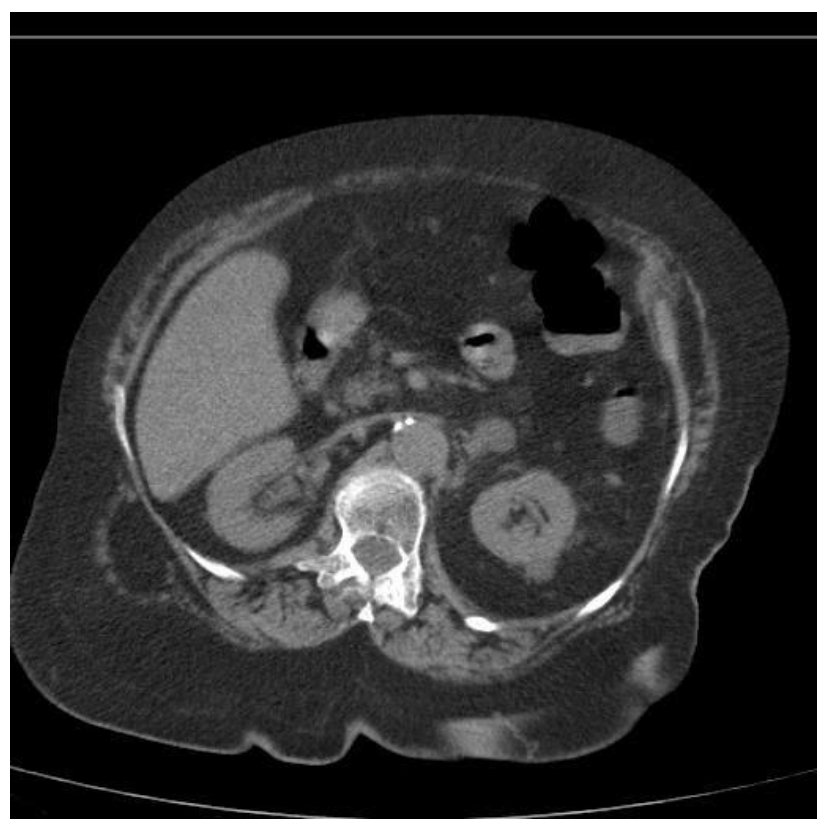

The treatment will always be surgical, aiming at the correction of the muscular defect of the abdominal wall and reduction of the hernia. It should be done at the earliest possible time (Renck, Gomes and Lopes Junior, 2009; Matos, Orioli, et al., 2011, Pereira, Souza, et al. It is important to remember that if there is any complication, such as bottlenecks, for example, it is indicated the anterior approach, which facilitates the exploration of viscera that are in the hernial sac (Espino, Silva, et al., 2002).

The postoperative period is common to all hernias and to date, there have been no cases of recurrence of this type of hernia (Renck, Gomes and Lopes Junior, 2009).In children, surgical repair should be performed between 6 and 12 months of life, and in adults, soon after diagnosis (Renck, Gomes and Lopes Junior, 2009). The use of polypropylene mesh is well accepted, especially when the defect is substancial (Alcoforado, Lira, et al., 2013). In general, Grynfeltt hernias when corrected as good as should be, have then a good evolution (Alcoforado, Lira, et al., 2013). 


\section{References}

Alcoforado, C. et al. Hérnia de Grynffeltt. (2013). ABCD Arquivos Brasileiros de Cirurgia Digestiva. 26 (3), p.241-243.

Alves, G.R.T. et al. (2011). Grynfeltt-Lesshaft hernia. Annals of Gastroenterology. 1(25), p.64.

Espino, J. A. R. et al. (2002). hernia Lumbar de Grynfelt-Lesshaft. A propósito de 2 casos. Revista Cubana de Cirugia. 41 (2), p.124-128.

Matos, N. C. et al. (2011). Hérnia lombar encarcerada: diagnóstico raro de abdome agudo obstrutivo. Arquivos Médicos dos Hospitais e da Faculdade de Ciências Médicas da Santa Casa de São Paulo. 56 (2). p.83-86.

Pereira, E. S. et al. (2012). Hérnia de Grynfeltt inicialmente diagnosticada como lesão neoplásica: relato de caso. Revista de Medicina e Saúde de Brasilia. 1(3), p.148-152.

Renck, D. V.; Gomes, L. D. M.; Lopes Junior, J. I. (2009). Hérnia lombar adquirida secundária do tipo Grynfeltt: relato de caso. Radiologia Brasileira. 42(2) p.137-138.

Zanini, M.; Timoner, F. R.; Machado Filho, C. D. (2004). Hérnia de Petit: comentário de um caso. Anais Brasleiros de dermatologia. 79(2) p.235-236.

\section{How to cite this article (APA format):}

Machado, R. S. S.; Brito, R. C. de; Frutuosos, J. F.; Sant'Anna, A. L.; Magalhães, F. A.; Machado, V. M. S. S.; Batista, H. M. T. (2019). Grynfeltt Hernia initially diagnosed as Lipoma: A Case Report. Am. In. Mult. J., April. (6) 3, 01-08.

Received: 03/29/2019

Accepted: 04/15/2019 